\title{
The value of digital archive film history: willingness to pay for film online heritage archival access
}

\author{
Ricky N. Lawton ${ }^{1}$ (D) . Daniel Fujiwara ${ }^{2}$. Ulrike Hotopp ${ }^{1,3}$
}

Received: 9 August 2019 / Accepted: 18 March 2021 / Published online: 24 June 2021

(c) The Author(s), under exclusive licence to Springer Science+Business Media, LLC, part of Springer Nature 2021

\begin{abstract}
With the passage of time, celluloid film degrades and valuable film history is lost, resulting in loss of cultural history which contributes to the shared sense of community, identify, and place at a local and national level. Despite the growth in digitised services for accessing cultural resources, to date no economic valuation has been performed on digital local history resources which are accessible online. Despite the recent emergence of online portals for digital cultural services in many countries (such as virtual tours of art galleries and digitisation of cultural archives) a shift which has accelerated in response to the Covid-19 epidemic, there remains a majorliterature gap around the value of digital culture. Failure to account for the value of digital archives risks sub-optimal allocation of resources to accessing and preserving these aspects of local cultural history. In response, we performed the first contingent valuation study to estimate willingness to pay for a free online film archive portal containing historical film footage for localities throughout the United Kingdom. Users were willing to pay an average hypothetical subscription for digital archive film services of $£ 38.52$ /annum. Non-users in the general population were asked their willingness to pay a hypothetical annual donation to maintain free public access (£4.68/annum on average). The results suggest that positive social value is gained from online access to digital archive film, and from knowing that the cultural heritage continues to be digitally accessible by the public for current and future generations. We outline how this evidence aligns with a theoretical framework of use and non-use value for digital goods and services extending beyond those who currently use the portal, to those introduced to it, and those in the general public who have never directly experienced the online archive service. We also report what we believe is the first application of Subjective Wellbeing analysis to engagement with a digital cultural service. The advantage of applying methods from economics to value cultural activities in monetary terms is that it makes emerging modes of digital cultural goods and services commensurable with other costs and benefits as applied to cultural policy and investment decisions, putting it on a level footing with physical cultural assets.
\end{abstract}

Extended author information available on the last page of the article 
Keywords Digital archive $\cdot$ Cultural value $\cdot$ Film history $\cdot$ Willingness to Pay · Contingent Valuation $\cdot$ Subjective wellbeing

\section{Introduction}

Cultural heritage is the legacy of physical artefacts and intangible attributes of society inherited from past generations (Willis, 2014). Increasingly, these artefacts take the form of audio-visual and electronic material. The formats on which this cultural heritage is stored are often at risk of becoming outdated and obsolete. Cultural heritage artefacts are to a greater or lesser extent unique and irreplaceable. Once they are gone, they may be lost forever to future generations. This means that efforts must increasingly be made to restore audio-visual material and convert it into formats that can preserve it for the future.

Organisations across the world are creating cultural databases whose contents are available to the general public. The British Library recently made its collection of ethnographic music available online free of charge and the National Film Board of Canada operates a stream-for-free archive of its documentaries, nature shows and animations, while UbuWeb collects and curates avant-garde cinema, sound poetry, music and text, that would otherwise be in storage at art museums or university collections, largely inaccessible to the general public.

Despite the recent emergence of online portals for digital cultural services in many countries (such as virtual tours of art galleries) and the digitisation of cultural archives (such as the British Library), this shift to digital services has not yet been reflected in the literature, which represents a major gap at the state of the art in cultural engagement. We anticipate that this shift to digital cultural engagement may experience a step change in the coming decade, especially in response to the 2020 COVID-19 pandemic, which led to the closure of cultural institutions for many months and an acceleration of their digital offer. It is therefore important that valuation research fill this gap in knowledge around digital cultural services.

The archival work behind this process must commonly be undertaken in a notfor-profit way by interest groups, charities and government-funded agencies. Nonetheless, evidence suggests that the act of archiving historic film and audio archives is widely valued by the general population (Ongena, 2013). While previous valuation studies have elicited the value that users and non-users hold for the archive work of institutions like the British Library (Pung et al., 2004), what has not been previously explored is the value of bringing archive film material to the public in digital format. Furthermore, given the shift towards online media in modern society, it is important to understand the benefits provided by bringing cultural heritage to the public through online portals that are designed to increase engagement and highlight the links between archive material and the local place and culture to which it is bound.

In the UK, film material has been archived and made available online for the first time to the public through the Britain on Film $(\mathrm{BoF})$ programme. It offers public access to curated film collections from the British Film Institute (BFI) National 
Archive and Regional and National Archives. ${ }^{1}$ The online service curates archive content into collections and allows users to search content linked to places of interest through the map search function on BFI Player. Underlying this is the work of the BFI National Archive provides preservation and restoration of digital film as part of the Unlocking Film Heritage programme.

Evidence has shown that public investment in cultural heritage provides value to individuals, society, and the economy (Bakhshi et al., 2015; Crossick \& Kaszynska, 2016; Eftec, 2005). Many of these values are 'non-market' in nature, in that cultural services, such as museums, libraries, and archives, are offered freely as 'public goods'. This means that there is no common standard of value that can be assigned to them. Over the past three decades there has been growing appreciation that the value of cultural heritage can be captured through economic valuations that draw on the empirical techniques of contingent valuation and revealed preference, in contrast to the formal designations and valuations of significance based on expert knowledge (Crossick \& Kaszynska, 2016; Noonan, 2003; Throsby, 2003; Willis, 2014).

The Cultural Value Project in the UK recommended the use of best practice contingent valuation $(\mathrm{CV})$ methods for valuation of cultural services and institutions (Crossick \& Kaszynska, 2016). We built on this work to design of three online surveys to assess the benefits of BoF on users who had experienced the service; and non-users in the general population who have not used the service previously. This allowed us to measure the value of digital access to cultural heritage through BoF directly on users, and more broadly, in the 'non-use values' held even by those in society who have not previously used the services. We apply a typology of use and non-use values for cultural heritage, and defined in the Total Economic (TEV) framework of use and non-use values for non-market valuation (Pearce \& O’zdemiroglu, 2002).

We are also interested in understanding the connections between access to cultural heritage and quality of life. The survey data enables us to compare difference in self-reported subjective wellbeing (SWB) between users and non-users. Alongside the CV figures, this provides supporting evidence that the preferences that individuals state for cultural heritage reflect the primary benefits stemming from welfare changes associated with archive film engagement. Our review of the literature shows that this is the first CV study of archive film in the UK and provides the first comprehensive study that shows the welfare benefits of storing and viewing heritage films online.

This is an important time to establish the value of digital resources like these, as policy in this area is in an early phase and research is catching up to the demands of cultural audiences for more digital services, especially in response to the Covid-19 epidemic. Robust valuation evidence can help policy-makers to identify investment decisions that have the greatest net benefit to society, including some which may be digital offers; can help to engage audiences who have traditionally be hard to reach by the cultural sector, such as people with disabilities and those from lower socioeconomic groups; and aid practitioners in identifying new revenue streams in terms

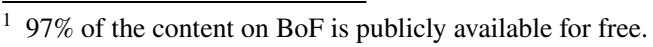


of the public's willingness to pay for different digital offers. The creation of a film archive portal containing local history footage represents a source of material of cultural and historical significance which could otherwise be lost. Conversely, investment made now can help to increase social welfare by ensuring greater access for all to consume digital cultural materials both now and in the future.

\section{Theoretical framework}

\subsection{Valuation of cultural services and institutions}

Cultural value can be defined as the worth attributed to cultural activities involving formal and informal, popular and commercial, and digital as well as physical forms of engagement and participation. How to understand and measure cultural value is the subject of significant debate in a number of disciplines including philosophy, economics and sociology, and many approaches have been developed and suggested. For example, there are theories that seek to understand cultural value in terms of its relationship to place and society, in terms of the construction of shared cultural values, in terms of spiritual values and intrinsic value, and in terms of its value to human welfare and quality of life (Throsby, 2001). This is true for physical culture, but also, increasingly, for the digital archives and services that allow people to access culture remotely.

While it is important to acknowledge that a range of approaches exist, including a combination of qualitative and quantitative methods, increasingly evaluation methods focus on those that can be used to assess cultural policy and investment using Cost-Benefit Analysis (CBA), whereby outcomes are valued in monetary terms and compared against the costs of investment in order to evaluate their value to society.

The advantage of applying methods from economics to value cultural goods and services in monetary terms is that it makes cultural goods and services-both physical and digital-commensurable with other costs and benefits within CBA as applied to cultural policy and investment decisions, putting it on a level footing with other policy areas. Valuation used in such an economic framework is concerned with how activities, such as engagement in arts and cultural heritage, impact on people's wellbeing (also known as quality of life, or utility in economics, see Kaldor, 1939).

This is grounded in one of the main ethical theories underlying policy decisions - Welfarism - a branch of consequentialism, which states that policies should be judged in terms of the outcomes they produce and what impact those outcomes ultimately have on welfare and personal wellbeing. ${ }^{2}$ This is ultimately a framework for thinking about how monetary values can be defined, categorised, and estimated for culture. However, it also has a broader use for policy makers in culture who can use it to structure arguments for the value of culture and to help articulate investment

\footnotetext{
2 Other ethical approaches also exist, including Sen's capabilities approach (Sen, 1985, 1999). The capabilities approach is a deontological moral approach in ethics which informs the Organisation for Economic Co-operation and Development (OECD) framework for measuring wellbeing (OECD, 2017).
} 
in cultural goods and services where there is not currently good quantitative valuation evidence.

Research eliciting economic values or benefits associated with access, preservation or restoration of cultural assets dates back to the 1980s when the first valuation studies in the field were conducted (for review, see Noonan, 2003; Throsby, 2003). Since then, many studies in the cultural sector have been conducted worldwide investigating a variety of benefits, both tangible and intangible. Stated preference (SP) methods enable the calculation of Total Economic Values (Pearce \& O'zdemiroglu, 2002), a value framework subdivided into Direct use benefits from digital cultural goods and services, like BoF, could include recreational, leisure, and entertainment activities, as well as education, inspiration and knowledge. Indirect use benefits of a film archive portal containing local history footage could arise in the form of enhanced community image, sense of place, and social interaction. A so-called option value can also be attached to potential future use of archive collections or the services that BoF provides (Mourato \& Mazzanti, 2002). Users may also hold non-use values. We can identify a primary categorisation of non-use values associated with digital cultural services, and non-use values associated with the archive work behind BoF. Non-use values can be described as: altruistic valueswelfare increases from knowing that others currently living will benefit; bequest values-welfare increases associated with knowing that future generations will benefit; and existence values - associated with welfare enhancements from knowing archive films are preserved and could be used in the future. ${ }^{3}$

\subsection{Economic valuation of digital cultural assets}

The emerging importance of digital cultural assets in terms of their aesthetic, archaeological, educational, intellectual, collective identity, artistic and financial contribution has hence motivated an increasing application of economic valuation methods with the aim of deriving estimates of monetary values of cultural institutions, assets, and services from a societal point of view (Throsby, 2001). Crossick and Kaszynska (2016) highlighted the diversity of platforms for culture and cultural heritage, but also the difficulty in attempting to measure a complete value of culture. Digital platforms and technologies, such those promoting BoF, provide access for people to connect with culture and cultural institutions where they might previously have been marginalised from access. Given that an individual's home is commonly now their primary place of cultural consumption (Crossick \& Kaszynska, 2016), there is a rise

\footnotetext{
${ }^{3}$ We note that many of the multiple benefits provided by cultural heritage are by their nature bundled together. Partial separate identification of some of the broader benefit categories of use and non-use may however be possible, with careful sample selection and survey design (following Bakhshi et al., 2015). As applied to the present study, this may include asking a separate WTP question for use aspects (access to $\mathrm{BoF}$ ), and non-use aspects (the archive work behind $\mathrm{BoF}$ ). However, in order to disentangle the different components of non-use value-existence, altruistic, and bequest-would require targeted follow-up questions such as those asked in (Andersson et al., 2012), which were not included in the current survey. This would be a useful addition to future research.
} 
in accessibility of cultural consumption, and co-production and user-generated content has increased (Crossick \& Kaszynska, 2016).

Brynjolfsson et al. (2019) attempted to estimate a monetary value for social media services (Facebook, WhatsApp, etc.) which provides engagement with friends and family online, through Stated Preference Discrete Choice Experiments on a sample of 426 Netherlands students. Willingness-to-accept values were determined for a scenario where respondents faced restricted access to free digital social media goods. ${ }^{4}$ Respondents were asked how much they would be willing to receive in exchange for giving up each platform for 1 month. To ensure incentive compatibility, their passwords were changed and protected in a sealed envelope. 'Whatsapp' rated the greatest WTA median average of $€ 535.73$ as respondents reported this was their main communication format with friends and family. In response, Sunstein (Sunstein undefined/ed) commented on the magnitude of this disparity and suggested that this reflects a 'superendowment effect'. Social media may be Wasting Time Goods-goods on which people spend time, but for which they are not, on reflection, willing to pay much (if anything). Research on the value of social media usage has been growing in recent years, with contributions from Allcott et al. (2020) using a randomised experiment to find that deactivating Facebook for 4 weeks increased subjective well-being.

The focus of this study is not on social media, but on digital services that allow the public to engage in culture and heritage remotely. The literature in this field is sparser. Cazzetta's (2008) thesis investigated the value of accessibility of digital content in the cinematographic heritage field using a CV method on a sample of 132 YouTube users who normally watch, upload and/or comment on heritage movies. Over $90 \%$ of respondents were willing to pay a hypothetical fee for downloading heritage movies with high definition (large files). Among those, $17 \%$ of the respondents expressed a WTP higher than \$7. Ongena's (2013) thesis explores the factors that contribute to the use of digital archives in the cultural heritage sector. The author assessed WTP for a digital audio-visual heritage service in the Netherlands using a general population sample of 205 adults. Results found that the majority (76.6\%) were not willing to pay (a large zero response). $12.2 \%$ were willing to spend $€ 0.50$ and $8.8 \%$ were willing to pay $€ 1.00$ per program. Only a small proportion $(2.5 \%)$ were willing to spend $€ 1.50$ or $€ 2.50$. There is a gap in the literature about the values that people have for digital archive film. The UK Film Council Report (Steele, 2004) found that although 'the literature on contingent valuation in relation to cultural heritage is now quite large, there appear to be very few studies applying it to the moving image'. One exception is Hobbs (2016) who developed an online survey to investigate the difference in WTP values between 'insiders' and 'outsiders' in short animation film online content. Insiders, those who had experience in animation (as a hobby, job, or through daily consumption), spent more hours consuming animation, indicated a greater interest in animation, and interacted with animation more than outsiders (those who watched purely for content). This increased experience resulted in insiders reporting higher willing-to-pay values $(M=£ 2.31)$ than outsiders $(M=£ 1.21)$ for online animation content. Thus, WTP

\footnotetext{
${ }^{4}$ Facebook, Instagram, Snapchat, Skype, WhatsApp, digital Maps, LinkedIn, and Twitter.
} 
value is highly dependent upon an individual's subjective experience value (i.e. their engagement value) of a good.

While the above-mentioned studies have researched values for online goods, we note the methodological limitations. Anchoring bias is likely to be introduced in the Cazzetta and Ongena studies by the limited payment range offered to respondents, while the robustness of the results may be called into question by the small sample sizes surveyed, and the fact that they are non-peer reviewed thesis papers.

WTP represents a monetary indicator of the welfare gain/loss experienced through engagement with a good/service, in this case cultural heritage. This welfare gain should be reflected in their overall quality of life, for which willingness to pay is a proxy. There have been limited efforts to date to assess the impacts on subjective wellbeing that stems from engagement in online cultural content. Wheatley and Bickerton (2017), who explore the relationship between engagement in arts (predominantly offline engagement at institutions) and subjective well-being, using UK data from understanding society. Frequency of engagement is central to positive wellbeing outcomes: only regular participation in arts activities generates positive effects. The findings also indicate even less frequent engagement in activities exhibiting cultural characteristics, e.g. museums/historical sites, has positive association with satisfaction. Fujiwara et al. (2017) conducted a large online survey with library visitors and non-visitors resident in the UK to estimate the association between library services and wellbeing. Library services included some online services like accessing information, and online training courses. Library use was positively associated with higher life satisfaction, higher happiness/momentary wellbeing, and a higher sense of purpose in life/eudaimonic wellbeing, as well as a general health measure, compared with non-users. However, we found no examples of subjective wellbeing studies around the benefits of archive film in particular, or online cultural services more broadly in the literature.

In short, the consumption of culture is changing, and researchers are yet to establish public values for this new content format. There are clear gaps in the existence of $\mathrm{CV}$ or wellbeing valuation studies on film and digital film archive content in the UK. Although there are some examples internationally, and a small body of literature on access to cultural content online, there are research gaps in valuation literature on digital archive film, and there appear to be no peer-reviewed studies of digital heritage content. There is also a need for greater understanding of the values people place on digital services which provide easier access to a large bank of cultural goods and services. This gap is particularly problematic given the growth of digital providers of cultural material in the past 5-10 years, and the likely importance of such services in the future. Our study therefore adds very significantly to knowledge in this area by applying best practice in $\mathrm{CV}$ developed in the cultural sectors over the past decades.

\section{Methodology}

\subsection{Survey samples}

Stated Preference (SP) surveys elicit the monetary value of non-market goods and services (measured as compensating or equivalent surplus) by directly asking 
people what value they attach to them (Bateman et al., 2002). By means of an appropriately designed questionnaire, a hypothetical market is described where the good or service in question can be traded. A sample of people (representative of the population of interest) are then directly asked about their WTP or WTA for a change in the level of provision of the good or service.

SP methods include Contingent Valuation (CV) which is used to value full policy/programme changes (e.g. full exclusion from the BoF service), while Discrete Choice Experiments (DCE) value changes in specific attributes of a good (e.g. provision of different types of material, formats, etc.) (Juutinen et al., 2011; Sriarkarin \& Lee, 2018; Zong et al., 2017). For a review of the advantages and disadvantages of DCE vis-à-vis CV see Hanley et al. (2001). In sum, we do not apply DCE in the current study, because DCE is aimed at valuing attributes rather than complete policy changes and in the current study we are interested in the overall value of $\mathrm{BoF}$ rather than the values of its constituent parts and $\mathrm{CV}$, rather than DCE, is designed to pick up overall value.

It is acknowledged that there are times when WTA is warranted, for example when property rights are such that respondents believe they have some intrinsic right to the good or service in question (culture is arguably a good example of such a case, but it is less clear in the current market for online content that this should always be the case). While it is true that under Hicksian welfare theory compensating surplus equivalent surplus should be loosely equal regardless whether the change in the good is framed as a loss or gain, evidence shows that WTA and WTP for the same goods differ on average by around 3 times (Kim et al., 2015). There are a number of implicit and explicit assumptions that are needed WTP to loosely equal WTA, related to discrete quantities (when the improvements are large (discrete) the associated equivalent surplus is no longer a function of income, see Kim et al., 2015) and substitutability (low substitutability between the environmental good and each of the private goods in the individual's utility function (Hanemann 1991).

However, even where such conditions do not exist, WTA-WTP disparity is found, especially for non-market good (Horowitz \& McConnell, 2002), even though the disparity can be reduced through greater incentive-compatibility (Koń \& Jakubczyk, 2019; Tunçel \& Hammitt, 2014).

As a consequence of this disparity, WTP has become the preferred monetary elicitation method in the CV literature, especially in empirical applications where the priority is to produce realistic valuation estimates that are less open to critiques of over-estimation due to hypothetical bias. However, a caveat is necessary for situations in which WTP values are used for cost benefit analyses. It may hold that for cultural goods and services which are public goods and are not profit-oriented, that the use of WTP measures and a focus on non-users could lead to low valuations compared to the use of WTA values. This could potentially justify negative investment decisions in the cultural sector. It is therefore necessary to consider the counteracting biases that may operate on SP values: the hypothetical biases that can lead to over-estimation of value in SP surveys, and the choice of WTP over WTA, which may be more practical from a survey design perspective, but can lead to an underestimation of values for public goods. 
We conducted three online surveys, each combining questions on usage and engagement with CV and SWB measurement. The first survey (Survey A- 'New Users') was composed of members of the general public who had not used the online portal before $(N=1000)$ who were asked to explore the service over a minimum of 2 days and then responded to a follow-up survey (final number of completes $=479$, $52 \%$ non-response). ${ }^{5}$

The second (Survey B-'Existing Users') was gathered from those who were using BoF on BFI Player and who were invited to take part in the survey through a pop-up window on the website. They were offered an incentive to complete the survey $^{6}$ (final number of completes $\left.=411\right)^{7}$

The third survey (Survey C-'Non-Users') was a nationally representative sample of the UK population (by gender, age and region) provided by an internet panel provider (final number of completes $=1,493){ }^{8}$ Approximately $10 \%$ of those in Survey $\mathrm{C}$ had used $\mathrm{BoF}$ in the past year.

To ensure representative with the general population, surveys $\mathrm{A}$ and $\mathrm{C}$ were set with nationally representative quotas for gender, age, and region using national UK averages from the Office for National Statistics' Annual Population Survey. For Survey B (Existing Users), we applied BFI Player user weights for gender and age (assembled between August 2015 and July 2016) to correct for slight over-representation of older people and a slight gender imbalance. We cannot discount the possibility that some types of users may be more likely to select into taking the survey. Some element of selection may also exist in survey A, where those with greater background interest in film and culture may have selected into exploring BoF, while those with less background interest abstained, or did not return to complete the follow-up survey. Unless otherwise stated we report weighted averages for the Existing User Survey B sample throughout the paper. ${ }^{9}$

\subsection{Survey instrument}

The survey was divided into four sections. The first section contained background questions on usage of BoF, enjoyment and satisfaction with different aspects of the digital service and technical elements, and opinions and attitudes around archive

\footnotetext{
${ }^{5}$ We acknowledge the risk that individuals may not have explored BoF, and responded falsely to the follow-up survey to gain the incentive. To counteract this risk, we added questions to Survey A for those who indicated that they had not used BoF in the last 2-7 days. These individuals were provided with a follow-up question asking them to confirm that they had not explored BoF. Those who indicated that they had not were given the opportunity to explore BoF over half an hour while the survey was put on hold. Those who agreed were timed out of the survey and only allowed to return to it after half an hour had elapsed.

${ }^{6}$ The incentive was a prize draw to win a year's subscription to BFI Player+

${ }^{7}$ Note, no data is available on response rate into the survey from the BFI Player website.

${ }^{8}$ Dates of the surveys: Survey A: 13th July-29th July 2016. Follow-up survey: 26th July 2016-4th August 2016. Survey B: 25th July-14 September, Survey C: 5th November-10th November.

${ }^{9}$ Note that final sample population numbers listed above are based on the exclusion of 'speedster' respondents who answered the survey in under 4 min and incomplete surveys (Survey A N=64; Survey B N=76; Survey C N=21).
} 
film and public spending. The second section asked three SWB questions: life satisfaction, happiness, and sense of purpose, on a scale of $0-10$ where $0=$ 'Not at all' and $10=$ 'Completely'. ${ }^{10}$ Pre-validated SWB scales were taken from the UK Office for National Statistics (Oguz et al., 2013), with minor adjustments to happiness 'in the last hour' in place of 'yesterday' to adjust to the in-the-moment nature of the survey (MacKerron \& Mourato, 2013). In the user survey (Survey B), respondents were asked which areas of BoF they had been using in the previous hour. In the general population survey, we asked what activities the respondent had been doing in the previous hour. ${ }^{11}$ This data was used for performing analysis of hedonic 'momentary' SWB.

The valuation section presented respondents with information on BoF, in terms of its services and the conservation work and research of archive film, and asked their familiarity with the information on a five-point Likert scale (1, not at all familiar; 5, extremely familiar).

A payment card elicitation method was adopted, with an open-end 'other' amount option to reduce anchoring bias set by the payment range (Bateman et al., 2002). ${ }^{12}$ The payment card method provides a balance to the theoretical ideal with the practical constraints of the project (specifically, the small sample size and potentially high zero response) (Bateman et al., 2002; Maddison \& Foster, 2003; Maddison \& Mourato, 2001). Respondents were asked a certainty question on the amount that they had stated (Bedate et al., 2009; Champ \& Bishop, 2001). Respondents were provided with cheap talk scripts asking them to be realistic, reminding them of the household budgetary constraints, and the existence of other cultural institutions that they may wish to spend their money on (Cummings \& Taylor, 1999; Lawton et al., 2019). ${ }^{13}$ Section 4 asked a set of standard socio-demographic questions for use in analysis. We undertook extensive testing of the draft survey instrument and hypothetical valuation scenarios.

There are a number of well-known potential biases in CV that can be problematic if not adequately addressed in the survey instrument and analysis (Bateman et al., 2002; Haab \& McConnell, 2002; Pearce et al., 2006). These include: hypothetical bias, where respondents overstate the amount they are willing to pay in the hypothetical situation, in relation to what they would pay in reality; starting point bias, and

\footnotetext{
${ }^{10}$ Overall, how satisfied are you with your life nowadays? ('Life satisfaction'; How happy were you feeling in the last hour or so? ('Happiness'); How worthwhile did what you were doing in the last hour or so feel? ('Purpose').

11 List of activities developed from the Mappiness iPhone Experience Sampling Method (ESM) (MacKerron \& Mourato, 2013).

12 WTP values were elicited using a payment card with value ranges differing between WTP questions and surveys: BoF subscription (Surveys A \& B): Value range of $£ 0$ to $£ 100$; Top-up donation for conservation work and research of archive film (Surveys A \& B): Value range of $£ 0$ to $£ 15$; BoF donation (General population Survey C): Value range of $£ 0$ to $£ 100$; Conservation work and research of archive film donation (General population Survey C): Value range of $£ 0$ to $£ 100$.

${ }^{13}$ Cheap talk script is a survey technique designed to reduce hypothetical bias in WTP estimates by reminding respondents of their budget constraints and availability of alternative goods, in order to make WTP values incentive compatible with standard welfare theory.
} 
payment vehicle bias. We note that the results in this study could have been affected by a number of different strategic biases, some of them balancing each other out.

The criticism of CV that has perhaps received greatest attention is hypothetical bias (Arrow \& Solow, 1993; Champ \& Bishop, 2001; Hausman, 2012), where individuals' stated WTP may be significantly larger than actual WTP due to the hypothetical nature of the survey. This arises mostly when a voluntary payment mechanism is used. In the case of this study the user sample were presented with a compulsory payment vehicle (increasing consequentiality) and told that they would have to pay to continue using $\mathrm{BoF}$, which was considered a realistic scenario and one that aligns with the online media marketplace. Piloting of the survey found that $70 \%$ of respondents found the scenario of a subscription charge for Britain on Film realistic.

To address this we included a certainty question in the surveys (e.g. 'How certain are you that you would really pay the amount indicated if asked?') (Champ \& Bishop, 2001). This allows us to provide sensitivity analysis on alternative levels of WTP associated with certainty of response, which is recommended when CV results are used in CBA (Haab et al., 2013). We aimed to use a payment vehicle which was as realistic as possible, a national tax over 3 years. We also use cheap talk entreaties (i.e. a script that explicitly describes this bias and asks respondents to avoid it) and oath scripts (i.e. asking respondents to agree to promise that they will respond to questions honestly) (Bakhshi et al., 2015; Lawton et al., 2019).

Payment vehicle bias is a form of strategic bias which occurs when respondents react in a strategic way to the payment vehicle they are presented with. For instance, an individual may object in principle to paying for a service that is already free (their endowment effect) and purposefully influences the survey results in a strategic way (e.g. by stating an extremely high or low WTP/WTA value) in order to help achieve their wish. Strategic bias can, therefore, lead to over or under statement of WTP or WTA (Throsby \& Withers, 1986). However, in the case of payment vehicle bias, we would expect protest responses to be expressed as protest zeros. We chose to keep possible protest zeros in the sample, because even though hit is possible that these respondents do not have a true zero WTP but some positive WTP which we do not observe, their exclusion would exert an upward effect on the calculation of mean WTP. Given the likely presence of other hypothetical biases which have an upward effect, we judged their exclusion would lead to an over-estimation of the value of BoF.

Starting point bias is introduced by the elicitation mechanism and occurs especially in dichotomous choice which presents the respondent with a random monetary figure (pre-scoped in piloting) which introduce a so-called anchoring or starting point bias by suggesting to the respondent the appropriate range of values to be elicited (Arrow \& Solow, 1993). Payment card approaches present respondents with a range of monetary amounts from which they are asked to pick their willingness to pay. This eliminates anchoring (and starting point) bias and provides a visual aid to the cognitive process of valuing the good (Bateman et al., 2002; Maddison \& Foster, 2003; Maddison \& Mourato, 2001). However, this approach is in turn vulnerable to biases by the range presented to the respondent. In this study we minimised the effects of the range presented by fully piloting the payment card range of WTP 
values with cognitive debrief questions to elicit the appropriateness of the range for the valuation exercise, ${ }^{14}$ and with the inclusion of an open-ended 'other amount' option contributes to reducing this effect.

The payment vehicle was scoped fully with the client and wider stakeholder group, consisting of UK Government economists. In the case of user samples, it was considered that alternative payment vehicles, such as increased national or local taxes, would produce a more severe protest response than a subscription to view, which is more commonplace in the online media marketplace. For non-users, it was considered that a non-compulsory donation was the most appropriate payment vehicle to reduce protest responses. The payment cards were capped at $£ 200$ and openend responses above $£ 250$ were removed as unrealistically high and indicators of strategic bidding (see Sect. 6.1 for discussion of rationale for excluding respondents from the study samples).

Follow-up questions asked respondents about their motivations for not being willing to pay/accept. This allows us to identify potential protest bids associated with the information or payment vehicle presented, which provides us with more confidence that respondents' stated values reflect the values they place in BoF. Contingent valuation scenarios.

In response to the different contexts for the three surveys, WTP scenarios, payment mechanisms and elicitation method differed between the user and general population surveys.

Surveys A and B (New and Existing Users) were designed to uncover the following values:

(a) the value of using BoF (via a monthly subscription fee);

(b) the non-use value of the research and archive work behind $\mathrm{BoF}$ (via a donation, elicited as a top-up to the subscription fee).

\footnotetext{
Main payment card question: Surveys A and B (New and Existing Users)

Imagine Britain on Film would now be available only to subscribers. Would you be prepared to pay a monthly subscription, even if only a small amount, for Britain on Film?

The subscription would allow you to continue to access Britain on Film as it currently is, and use all content and services, including the map interface. Note that this Britain on Film subscription is totally separate to any BFI Player subscription. This amount would be additional to the subscription that you currently pay for the BFI Player + or for membership of the BFI

Yes/Maybe/No
}

\footnotetext{
${ }^{14}$ We used the pilot phase to test the appropriateness of the payment card range for the Britain on Film subscription WTP question (£0-£100). The maximum value selected was $£ 35(\mathrm{n}=1)$. However, one respondent selected an 'other' amount of $£ 150$. Based on this range we kept the subscription WTP range unchanged. We also tested the top-up donation range of $£ 0-15$. The maximum value selected was $£ 15$ $(n=1)$, and the next highest $£ 6(n=1)$, then $£ 5(n=6)$. Based on this range we recommend keeping the WTP range as it is for the top-up donation WTP question.
} 
Please think about how much Britain on Film is worth to you, if anything. Looking at the list of amounts below, what is the maximum you would be willing to pay, as a monthly subscription, to keep access to Britain on Film as it currently is? The subscription can be cancelled at any time

Studies have shown that many people answering surveys such as this one, say they are willing to pay more than they would actually pay in reality. So please think about this question as if it were a real decision and you were actually making a payment for real. Please do not agree to pay an amount if you think you cannot afford it, if you feel you have paid enough already, or have other things to spend your money on. Also, this question is just about the currently free to access Britain on Film, and not about other services provided by the BFI Player. Remember also that content which is currently behind a paywall will continue to be available separately on a different subscription basis

Survey C (Non-Users) was designed to uncover:

(c) the non-use value of BoF (via an annual donation);

(d) the non-use value of the research and archive work behind BoF (via an annual donation).

Main payment card question: Survey $\mathbf{C}$ (Non-Users) In the next set of questions, we are interested to know how much, if anything, you would be prepared to donate, on top of any existing BFI membership, to support each of these programmes (Britain on Film and the BFI's conservation work and research of archive film) separately. It might be that you value both programmes, or just one of the programmes, or none of the programmes. We will ask you about willingness to donate to each programme in turn

Firstly, would you be prepared to make an annual donation, even if only a small amount, to maintain free access to Britain on Film for everyone? The donation would allow everyone to continue to access Britain on Film as it currently is, and use all content and services, including the map interface. This amount would be additional to the subscription that you currently pay for BFI Player + or for membership of the BFI

Yes/Maybe/No

Please think about how much Britain on Film is worth to you, if anything. Looking at the list of amounts below, what is the maximum you would be willing to pay, as an annual donation, to keep access to Britain on Film as it currently is?

Studies have shown that many people answering surveys such as this one, say they are willing to pay more than they would actually pay in reality. So please think about this question as if it were a real decision and you were actually making a donation for real. Please do not agree to pay an amount if you think you cannot afford it, if you feel you have paid enough already, or have other things to spend your money on. Also, this question is just about the currently free to access Britain on Film, and not about other services provided by the BFI Player. Remember also that content which is currently behind a paywall will continue to be available separately on a different subscription basis

\subsection{Analysis}

\subsubsection{Contingent valuation analysis}

We calculated nonparametric mean and median WTP from the mid-point between the amount chosen on the card and the next amount up. The latter is theoretically consistent with the statistical theory for calculating WTP from interval data (Cameron \& Huppert, 1989). Use of a payment card elicitation mechanism means that 
respondents' stated values must be taken as a lower bound of their actual willingness to pay (Bateman et al., 2002), because the actual amount they are willing to pay will lie somewhere in between the amount they choose and the next amount on the payment card. All those who responded that were not willing to pay were coded as $£ 0$ bids. We explored possible protest bids (invalid positive WTP values) by analysing the reasons given by respondents for being willing or not willing to pay. We removed individuals who gave inconsistent reasons for their stated willingness to pay. ${ }^{15}$

Using the mean WTP rather than the median is good practice in CV studies (Vaughan et al., 2000). The mean is relevant if the context of the valuation exercise is cost benefit analysis, because it represents an average WTP for the population which can be aggregated (by the population size) to derive the total WTP across the population. In general it is recommended that if aggregated WTP for benefits outweighs costs, a project should proceed (Pearce \& O’zdemiroglu, 2002).

The following regression model was used as part of the validation process to test that factors that are theoretically expected to affect WTP (such as income) and other factors that are known from the literature to have an effect e.g. positive attitudes towards film and culture (Bakhshi et al., 2015) are performing in the expected direction:

$$
W T P_{i}=\alpha+\beta_{1} X_{i}+\varepsilon_{i}
$$

where $W T P_{i}$ is the amount the individual $i$ has stated they are willing to pay (midpoint), $\alpha$ is the deterministic factor and $\varepsilon$ is the error term containing unobserved factors that determine willingness to pay. In $X_{i}$ we control for the observed determinants of willingness to pay (Bateman et al., 2002).

We estimated Eq. (1) with socio-demographic variables, variables capturing experience of $\mathrm{BoF}$, and attitudes, opinions, and proxy variables for cultural engagement for four models:

i. User subscription WTP for access to archive film

ii. User donation WTP for digital film archive work

iii. Non-user donation to support free access to online digital film archive portal

iv. Non-user donation to support archive work.

Model covariates were chosen within three groups. (A) Demographic variables were chosen based on those theoretically associated with WTP or identified in previous CV studies, including age, income, gender, education and marital status (following Bateman et al., 2002); (B) experience of BoF in terms of the survey answered (first time, existing (one-off) and existing (repeat) user, and self-reported enjoyment,

\footnotetext{
15 In the case of WTP for BoF, these included the statements that 'my WTP was in support for British film in general', and those who stated they didn't 'believe [they] would have to pay' (number of individuals were excluded: Survey A N=24; Survey B N=16; Survey C N=84). In the case of WTP for conservation work and research of archive film, these included those who stated that 'it seemed right thing to do' and those who stated they didn't 'believe [they] would have to pay' (number of individuals were excluded: Survey A N=34; Survey B N=11; Survey C N=101).
} 
satisfaction, and familiarity with $\mathrm{BoF}$; (C) general engagement with culture and film, including self-reported knowledge of film, prioritisation of spending for arts, culture, heritage and museums, having recently used a similar digital platform, and being member of heritage, conservation or other similar organisation, including BFI or BFI Player + subscriber. We ran residuals analysis which showed some autocorrelation, with adjacent residuals negatively correlated (Appendix 1). This demonstrates a non-normal error distribution. We therefore concluded that nonparametric statistical tests of difference should be applied to WTP data for robustness.

\subsubsection{Subjective wellbeing analysis}

We assessed the relationship between use of BoF and different non-cultural activities and SWB measures, in terms of individuals' momentary feelings of happiness or sense of purpose (hedonic wellbeing) (Kahneman et al., 2004). ${ }^{16}$

The presence of an online User (Survey B) and Non-User (Survey C) sample allows us to collect SWB data on how the respondent reports their SWB in the past hour, and to link that to the activity they were doing. In the case of BoF Users in Survey B, we know that this time has been spent accessing online archive film. In the case of Non-Users in the general population (Survey C), we elicit their activity in the past hour from a multiple-choice list (following the Experience Sampling Method; Csikszentmihalyi \& Hunter, 2003; MacKerron \& Mourato, 2013). This allows us to compare the associations between recent use of BoF to the range of other activities that an individual reports having been doing in the last hour using the following econometric model:

$$
S W B_{i}=\alpha+\beta_{1} A_{i}+\beta_{2} X_{i}+\varepsilon_{i}
$$

where $S W B_{i}$ is individual $i$ 's subjective wellbeing (happiness or purpose) over the previous hour; $A_{i}$ is a list of activities that the individual undertook during this period (where working/studying is used as the reference case in the models); $X_{i}$ is a vector of control variables and $\varepsilon_{i}$ is an error term. We use the following variables to control for selection into certain activities: age, gender, health, income, marital status, education, parental status, employment status, and current life satisfaction. All these variables have been shown in the literature to correlate with happiness, and may also correlate with the propensity to select certain activities (Fujiwara \& MacKerron, 2015).

We note the following caveats in all of the statistical analyses. Due to the observational nature of the data (i.e. the study is not based on data from experiments like randomised trials), the samples are non-random and causation cannot be directly inferred and future research should consider this further. The main determinants of SWB have been controlled for, but it should be recognised that the impact estimates may be biased to some degree if there are confounding factors that have not been

\footnotetext{
${ }^{16}$ In ESM, participants are asked to stop at certain times and to make notes of their experience in real time.
} 
controlled for in the analysis (Ferrer-i-Carbonell \& Frijters, 2004; Daniel Fujiwara \& Campbell, 2011). This is a risk with any wellbeing analysis using non-experimental data. Notwithstanding, multiple regression analysis (or similar types of analyses based on the same fundamental assumptions such as matching estimators) have been used extensively in the wellbeing and policy evaluation literature (Clark \& Oswald, 2002; Dolan et al., 2011; Ferrer-i-Carbonell \& Frijters, 2004).

\section{Results}

\subsection{Descriptive statistics}

Table 1 summarises key socio-economic characteristics across the three survey samples. We perform t tests to compare samples between New and Existing Users (Survey $\mathrm{A}$ and $\mathrm{B}$ ) and between Existing Users and Non-Users (Survey B and C). ${ }^{17}$

There are a number of statistically significant differences between the sample socioeconomic characteristics across the surveys. Two-sided t tests show that Existing Users (Survey B) were significantly more likely to be university educated $(63 \%, p=0.000)$, be in employment $(63 \%, p=0.001)$, and be living in London $(22 \%$, $p=0.000)$ than the new users and general population sample. Existing Users had a significantly smaller proportion of females $(36 \%, p=0.000)$ compared to the other samples. This suggests some selection of more educated, London-based males into the BoF user sample. ${ }^{18}$

Existing Users had significantly higher levels of self-reported health $(78 \%, p=0.000)$ compared to other samples, and were more likely to identify themselves as lesbian, gay, or bisexual $(11 \%, p=0.000)$, which is considerably higher than the $1.7 \%$ reported in the UK Annual Population Survey (APS). ${ }^{19}$ There was a lower proportion of individuals of Black, Asian and Minority Ethnic status among Existing Users (7\%) compared to Non-Users in the general population sample, but this difference was not statistically significant $(p=0.997)$. Existing Users were significantly more likely to be members of BFI or subscribers to BFI Player $+(19 \%$, $p=0.000)$. They were also significantly more likely to place heritage, arts, museums and culture amongst the three top priorities for public spending $(37 \%, p=0.000)$, indicating that those with pre-existing interest in cultural heritage are more likely to explore BoF (self-selection into the existing user sample, which is to be expected).

\footnotetext{
17 The comparison between the general population and new user survey is less relevant to our analysis, since the initial panel sample for survey A was nationally representative.

${ }^{18}$ This accords with web analytical data on BoF service users (38\% of BoF users between August and September 2016 were female).

19 https://www.ons.gov.uk/peoplepopulationandcommunity/culturalidentity/sexuality/bulletins/sexua lidentityuk/2015
} 
Table 1 Sample sociodemographic characteristics

\begin{tabular}{llll}
\hline & Survey A. new users & $\begin{array}{l}\text { Survey B. } \\
\text { existing } \\
\text { users }\end{array}$ \\
& \multicolumn{3}{l}{ Survey C. non-users } \\
\hline Female (\%) & $53.2^{*}$ & 36.2 & $51.2^{*}$ \\
Age (mean) & $51.5^{*}$ & 47.1 & 46.6 \\
Household income (£, mean) & $£ 32,964^{*}$ & $£ 36,190$ & $£ 32,518^{*}$ \\
Dependent children under 16 years (\%) & 21.5 & 19.5 & $25.1^{*}$ \\
Married/with partner (\%) & $64.3^{*}$ & 55.3 & 57.1 \\
University education (\%) & $45.6^{*}$ & 63.3 & $40.4^{*}$ \\
In employment (full-time, part-time, self- & $52.1^{*}$ & 63.2 & $53.9^{*}$ \\
employed) \% & & & \\
East Anglia & 12.7 & 10.5 & 9.0 \\
London & 5.8 & 6.0 & 5.9 \\
North East & $6.1^{*}$ & 22.1 & $9.6^{*}$ \\
North West & 4.0 & 3.5 & 5.0 \\
Northern Ireland & 12.3 & 8.6 & $12.9^{*}$ \\
Scotland & 2.3 & 1.1 & 2.1 \\
South Centre of England & 7.9 & 7.3 & 9.5 \\
South East & 12.5 & 12.6 & 13.2 \\
South West & 12.3 & 10.2 & 9.2 \\
Midlands & 5.0 & 3.7 & $6.1^{*}$ \\
Wales & 6.7 & 7.2 & 8.0 \\
Rural (\%) & 31.7 & 27.7 & 31.3 \\
Health (good, very good, excellent) (\%) & $68.7^{*}$ & 77.9 & $73.0^{*}$ \\
Ethnicity (BAME) & 7.4 & 7.4 & 10.1 \\
Sexuality (LGBT) & $4.3^{*}$ & 11.2 & $7.6^{*}$ \\
Member of BFI or BFI player + subscriber (\%) & $2.5^{*}$ & 18.6 & $3.3^{*}$ \\
Heritage, arts, museums and culture amongst & $14.6^{*}$ & 37.3 & $9.0^{*}$ \\
the 3 top priorities for public spending (\%) & & 411 & 1493 \\
Total & 479 & & \\
\hline & & & \\
\hline
\end{tabular}

Gross annual household income; averages computed using the midpoints of the income and age categories. Legend: ${ }^{*} p<0.05$ Indicates significant difference from existing user sample (Survey B) $(t$ test). $B A M E$ black and minority ethnicity, $L G B T$ lesbian, gay, bi and transsexual

Table 2 Willingness to pay in principle for online access to archive film (Britain on Film)

\begin{tabular}{|c|c|c|c|c|c|c|}
\hline & \multicolumn{2}{|c|}{$\begin{array}{l}\text { Survey A. new } \\
\text { users }\end{array}$} & \multicolumn{2}{|c|}{$\begin{array}{l}\text { Survey B. Exist- } \\
\text { ing users }\end{array}$} & \multicolumn{2}{|c|}{$\begin{array}{l}\text { Survey C. non- } \\
\text { users }\end{array}$} \\
\hline & $N$ & $\%$ & $N$ & $\%$ & $N$ & $\%$ \\
\hline Yes & 51 & 10.7 & 79 & 19.2 & 112 & 7.5 \\
\hline Maybe & 216 & 45.1 & 214 & 52.1 & 648 & 43.4 \\
\hline No & 212 & 44.3 & 118 & 28.7 & 733 & 49.1 \\
\hline Total & 479 & & 411 & & 1493 & \\
\hline
\end{tabular}

All no responses coded as $£ 0$ for WTP analysis. Sample weighted by existing user (Survey B) weights 


\subsection{Willingness to pay estimates}

Table 2 shows that in the New User survey, 56\% of respondents would or may in principle be willing to pay a subscription fee to access $\mathrm{BoF}$. A slightly higher proportion (71\%) of Existing Users would or may in principle be willing to pay something towards BoF compared to new users (56\%). We would expect to find that Existing Users (Survey B) would be more likely to indicate a positive willingness to pay toward $\mathrm{BoF}$, given that they have had more experience, and therefore gained greater welfare improvements, from their engagement with archive film. ${ }^{20}$ Of the three groups, Non-Users had the lowest proportion (51\%) indicating they 'would' or 'may in principle' be willing to pay towards BoF. Nonetheless, we note the low zero response rate in Survey B in contrast to other CV results in this sector (e.g. Ongena, 2013), which may indicate that existing users have a higher appreciation, and therefore willingness to pay in principle, for the service, although this result could also be driven by the self-selection of those with higher levels of cultural engagement into the Existing user sample.

Table 3 shows that among New Users (Survey A), mean willingness to pay for a monthly subscription to Britain on Film is $£ 2.54$ (median 63p). The mean WTP for a top-up monthly voluntary donation to support the archive work behind BoF is $£ 1.67$ (median 63p). Among Existing Users (Survey B) mean willingness to pay for a monthly subscription for BoF is slightly higher, at $£ 3.21$ (median £2.25), as is the mean WTP for a top-up monthly voluntary donation to support the archive work behind $\mathrm{BoF}$, at $£ 2.26$ (median £1.25). Existing Users have higher mean WTP (£3.21) compared to New Users (£2.54), although this difference is not significant using nonparametric Wilcoxon-Mann-Whitney tests.

Among Non-Users, Survey C provides a mean annual willingness to pay of $£ 4.68$ for an annual donation (median $£ 0$ ) to support continued free public access to $\mathrm{BoF}$ (equivalent to $39 \mathrm{p}$ per month). Non-User mean WTP to support the research and archive work behind $\mathrm{BoF}$ (annual donation) at $£ 3.44$ (equivalent to $29 \mathrm{p}$ per month, median $£ 0$ ). This suggests that the general population has a lower WTP for the research and archive work aspects of BoF than for maintaining free public access to BoF.

WTP for access to archive film is in all cases higher than WTP to support the archive work behind BoF. We would expect this to be the case, given that WTP for the archive work is elicited as a top-up/additional donation. We would expect this to be the case among BoF users who gain direct benefits from the service. Nonetheless, we still find a positive WTP for the archive work for both users and non-users.

\footnotetext{
20 Note that, when asked the actual WTP question, and faced with a list of possible amounts, a total of $4 \%$ of those new users saying they were willing to pay for a subscription were found to have a zero willingness to pay amount. We coded all individuals who stated that they would not be willing to pay in principle for BoF a $£ 0$ for the purposes of WTP analysis. Five per cent of existing users who said that they were willing to pay for a subscription were found to have a zero willingness to pay, while of the general population sample this figure was $7 \%$. The highest available option was not recoded, given that open space was provided for other values. The highest available option was not recoded, given that open space was provided for other values and was coded as missing.
} 


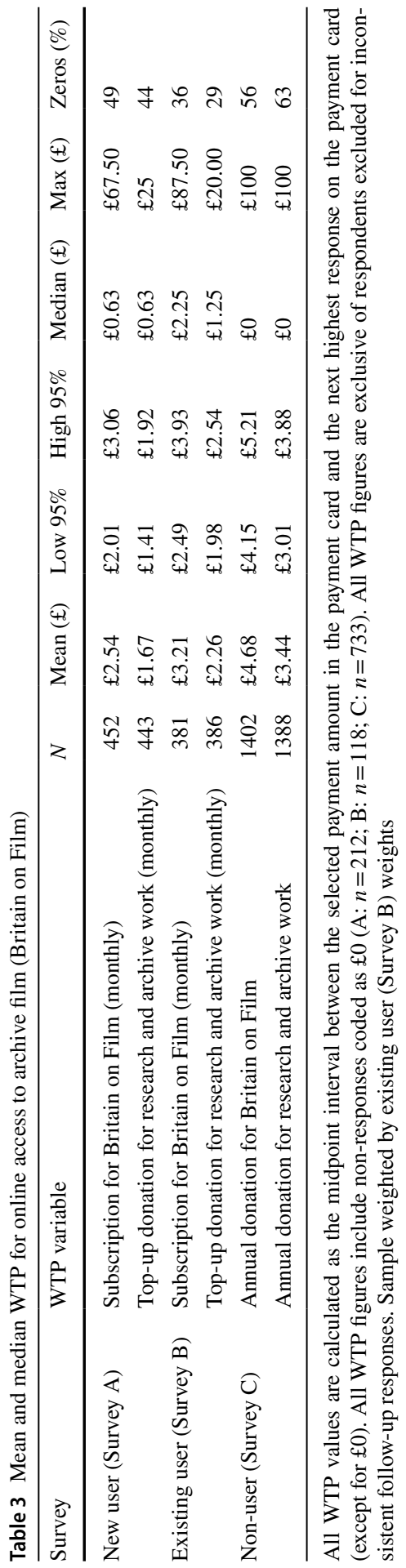




\subsection{Validity testing: factors associated with WTP values}

We check the validity of our results by testing that WTP is associated with theoretically consistent sociodemographic, behavioural, and attitudinal factors (following Bateman et al., 2002). These variables were collected through the primary survey which asked background questions related to cultural engagement, engagement with $\mathrm{BoF}$, and motivations behind stated preferences. Table 4 shows the factors associated with willingness to pay a monthly subscription and to donate to research and archive work for New and Existing Users, controlling for a range of factors.

In line with theoretical expectations, income has a significant and positive association with WTP to access $\mathrm{BoF}$ and willingness to donate for research and archive work. We find a positive association between retirement status and willingness to donate to research and archive work. Employment also has a significant and positive association with willingness to pay a subscription, in addition to the income effect.

In terms of use and experience of the archive film service, user WTP for subscription to BoF and a donation to support the archive work is significantly and positively associated with time spent on the service. Familiarity with the information on the archive film service is a significant and positive driver of WTP. Enjoyment of the service is significantly and positively associated with both willingness to pay a subscription and willingness to pay a donation to support the archive work.

Most variables included as more general proxies for cultural engagement are not significantly associated with WTP subscription or donation. The exception is agreement with the statement that $\mathrm{BoF}$ stopping would reduce life satisfaction, which is significantly and positively associated with WTP subscription and donation.

Table 5 shows the results for factors associated with willingness to pay an annual donation towards BoF and its research and archive work within the general population sample.

Again, income is significant and positively associated with willingness to pay for donation. This is consistent with previous CV studies of cultural institutions which find that individuals earning higher income are more likely to pay more to support the work of cultural institutions (Noonan, 2003). Being familiar with BoF has a large positive association with willingness to donate. Similarly, those familiar with the film archive have a higher willingness to donate to the archive work behind BoF.

Those who indicated that the archive film service stopping for a year would reduce their life satisfaction is significantly and positively associated with higher willingness to pay a subscription and a top-up donation. Being a member of a heritage, conservation or other similar organisation has a significant and positive association with willingness to pay for a subscription and to donate. The same holds for having general or specialist knowledge of film and willingness to pay for subscription.

We note the relatively low model fit in the OLS regressions in Table 5 (around $13-15 \%$ as measured in the R-squared value). We explored alternative model specifications to identify better model fit for the data. Given that the dependent variable (WTP) is ordinal in nature and zero-inflated, it may have been expected that an ordinal regression would be better suited to this kind of data. However, our exploration found a reduction in model fit associated with ordinal regressions in all cases: 
Table 4 Factors associated with user WTP for Britain on Film (subscription) and the research and archive work behind Britain on Film (top-up donation) (new and existing users, Survey A and Survey B)

\begin{tabular}{|c|c|c|c|c|}
\hline \multirow[t]{2}{*}{ Variable } & \multicolumn{2}{|c|}{$\begin{array}{l}\text { Subscription WTP for } \\
\text { access to archive film }\end{array}$} & \multicolumn{2}{|c|}{$\begin{array}{l}\text { Donation WTP for } \\
\text { digital film archive } \\
\text { work }\end{array}$} \\
\hline & $b$ & $\mathrm{Se}$ & $b$ & $\mathrm{Se}$ \\
\hline Gender (female) & -0.162 & 0.342 & -0.268 & 0.199 \\
\hline Age $(\log )$ & 0.468 & 1.064 & -0.157 & 0.382 \\
\hline Income $(\log )$ & $1.038 * * *$ & 0.316 & $0.270^{* *}$ & 0.127 \\
\hline BAME & 0.170 & 0.639 & 0.709 & 0.442 \\
\hline Education (university) & -0.441 & 0.373 & 0.225 & 0.196 \\
\hline Married/with partner & 0.036 & 0.304 & -0.350 & 0.237 \\
\hline Employed & $0.757^{*}$ & 0.454 & 0.234 & 0.268 \\
\hline Student & 0.318 & 0.902 & 0.170 & 0.601 \\
\hline Retired & 0.661 & 0.643 & $0.718^{* *}$ & 0.365 \\
\hline Children & 0.406 & 0.436 & 0.344 & 0.250 \\
\hline Disabled & 1.113 & 0.899 & 0.203 & 0.316 \\
\hline London & -0.569 & 0.521 & 0.454 & 0.366 \\
\hline Rural & -0.341 & 0.322 & -0.227 & 0.201 \\
\hline One-off user & $1.120 *$ & 0.577 & 0.291 & 0.243 \\
\hline First time user & 0.816 & 0.550 & $0.508^{*}$ & 0.285 \\
\hline Time spent on Britain on Film (hours) in last two days & $0.644 * * *$ & 0.236 & $0.161^{*}$ & 0.096 \\
\hline Enjoyment of BoF (enjoy/a lot) & $0.619^{* *}$ & 0.304 & $0.650 * * *$ & 0.200 \\
\hline Satisfied with content & 0.588 & 0.370 & 0.145 & 0.264 \\
\hline Familiarity with BoF & $2.546^{* *}$ & 1.022 & NA & NA \\
\hline Familiarity with archive work & NA & NA & 0.446 & 0.387 \\
\hline Arts, culture, heritage and museums are a fiscal priority & 0.025 & 0.438 & 0.337 & 0.260 \\
\hline General or specialist knowledge of film & 0.438 & 0.328 & 0.160 & 0.224 \\
\hline Recently used a digital platform & 0.556 & 0.397 & 0.192 & 0.250 \\
\hline $\begin{array}{l}\text { Member of heritage, conservation or other similar organi- } \\
\text { sation, including BFI or BFI Player + subscriber }\end{array}$ & 0.135 & 0.435 & 0.216 & 0.240 \\
\hline$B o F$ stopping would reduce my life satisfaction & $1.786 * * *$ & 0.484 & $0.852 * * *$ & 0.232 \\
\hline Constant & $-14.158 * * *$ & 4.327 & -2.302 & 1.884 \\
\hline Observations & 711 & & 703 & \\
\hline $\mathrm{F}$ & 3.621 & & 4.868 & \\
\hline $\mathrm{R}$ squared & 0.153 & & 0.131 & \\
\hline
\end{tabular}

*** significance at $<1 \%$; **significance at $<5 \%$; *significance at $<10 \%$. Reference group: (i) for gender ref=female; (ii) for education ref=all qualifications under Degree; (iii) for children ref=no children; (iv) for one-off and first-time user ref=repeat user. Heteroskedasticity-robust standard errors. Note, recommend friend excluded from model due to lower sample size. Likely to use BoF again excluded due to collinearity with enjoyment of BoF. Residuals analysis reported in Appendix 1

for Survey A\&B, R-squared in the WTP model for access to archive film model fit was $5 \%$ in the ordinal model, compared to $15 \%$ in the OLS regression, and in the Donation WTP for digital film archive work model, fit was $6 \%$ in the ordinal model 
Table 5 Factors associated with general population willingness to pay an annual donation for Britain on Film and (separate) annual donation to research and archive work (Survey C)

\begin{tabular}{|c|c|c|c|c|}
\hline \multirow[t]{2}{*}{ Variable } & \multicolumn{2}{|c|}{$\begin{array}{l}\text { Donation to support } \\
\text { free access to online } \\
\text { digital film archive } \\
\text { portal }\end{array}$} & \multicolumn{2}{|c|}{$\begin{array}{l}\text { Donation to sup- } \\
\text { port archive work }\end{array}$} \\
\hline & $b$ & $\mathrm{Se}$ & $B$ & $\mathrm{Se}$ \\
\hline Gender (female) & $-0.993 *$ & 0.544 & $-0.865^{*}$ & 0.453 \\
\hline Age (log) & $2.549 * *$ & 1.221 & 0.635 & 1.015 \\
\hline Income (log) & $1.146 * *$ & 0.584 & $1.165^{* *}$ & 0.501 \\
\hline BAME & 0.959 & 1.373 & 0.346 & 1.132 \\
\hline Education (university) & -0.446 & 0.606 & 0.233 & 0.473 \\
\hline Married/ with partner & -0.923 & 0.694 & $-1.173 * *$ & 0.525 \\
\hline Employed & 0.671 & 0.741 & $0.857 *$ & 0.472 \\
\hline Student & 1.455 & 1.331 & 0.61 & 1.052 \\
\hline Retired & 0.11 & 0.983 & 0.916 & 0.688 \\
\hline Children & -0.458 & 0.798 & -0.146 & 0.718 \\
\hline Disabled & 1.572 & 1.164 & 1.707 & 1.085 \\
\hline London & 1.301 & 1.352 & 1.64 & 1.276 \\
\hline Rural & 0.394 & 0.608 & 0.151 & 0.453 \\
\hline Familiarity with BoF & $8.064 * * *$ & 2.376 & NA & NA \\
\hline Familiarity with archive work & NA & NA & $6.483 * * *$ & 2.486 \\
\hline Arts, culture, heritage and museums are a fiscal priority & 0.268 & 1.044 & 1.228 & 1.042 \\
\hline General or specialist knowledge of film & $1.399 * *$ & 0.602 & 0.844 & 0.532 \\
\hline Recently used a digital platform & 1.014 & 0.649 & $1.014 * *$ & 0.441 \\
\hline $\begin{array}{l}\text { Member of heritage, conservation or other similar organi- } \\
\text { sation, including BFI or BFI Player + subscriber }\end{array}$ & $2.424 * * *$ & 0.770 & $2.465 * * *$ & 0.689 \\
\hline Britain on Film stopping would reduce my life satisfaction & $4.335^{* * *}$ & 1.049 & $3.173 * * *$ & 0.970 \\
\hline Constant & $-19.742 * * *$ & 7.300 & $-13.677^{*}$ & 7.063 \\
\hline Observations & 1230 & & 1225 & \\
\hline $\mathrm{F}$ & 6.083 & & 5.713 & \\
\hline $\mathrm{R}$ squared & 0.141 & & 0.146 & \\
\hline
\end{tabular}

${ }^{* * * *}$ Significance at $<1 \%$; $* *$ significance at $<5 \%$; *significance at $<10 \%$. Reference group: (i) for gender ref $=$ female; (ii) for education $r e f=$ all qualifications under Degree; (iii) for children ref $=$ no children; (iv) for new user ref=existing user. Heteroskedasticity-robust standard errors. Residuals analysis reported in Appendix 1

compared to $13 \%$ in the OLS model; for Survey C, R-squared in the WTP for access to archive film model was $5 \%$ in the ordinal model compared to $14 \%$ in the OLS regression, and in the Donation WTP for digital film archive work model, fit was 6\% in the ordinal model compared to $15 \%$ in the OLS model. The key drivers of WTP such as household income and indicators of cultural engagement remain significant in the ordinal model as they were in the OLS model, giving us greater confidence in the internal validity of the results. We report the alternative model specification results in Appendix 2, but focus on OLS results in the main report. 
Table 6 Association between activities and happiness and sense of purpose (worthwhile) in the last hour

\begin{tabular}{|c|c|c|c|c|}
\hline & \multicolumn{2}{|l|}{ Happiness } & \multicolumn{2}{|l|}{ Purpose } \\
\hline & $b$ & $\mathrm{Se}$ & $b$ & $\mathrm{Se}$ \\
\hline Used Britain on Film in last hour & $0.184 *$ & 0.098 & $0.593 * * *$ & 0.139 \\
\hline \multicolumn{5}{|l|}{ Other activities } \\
\hline Browsing the Internet, texting, email, social media & 0.073 & 0.114 & -0.077 & 0.166 \\
\hline Care or help for adults & 0.224 & 0.247 & $1.199 * * *$ & 0.264 \\
\hline Childcare, playing with children & $0.683^{* * *} *$ & 0.214 & $1.452 * * *$ & 0.307 \\
\hline Computer games, iPhone games, other games, puzzles & $0.440^{*}$ & 0.235 & 0.186 & 0.378 \\
\hline Cooking, preparing food & $0.348^{*}$ & 0.182 & $0.413 *$ & 0.237 \\
\hline Cultural activity & 0.392 & 0.317 & $1.204 * * *$ & 0.432 \\
\hline Eating, snacking, drinking tea/coffee & $0.472 * * *$ & 0.145 & $0.436 * *$ & 0.211 \\
\hline Hobbies, arts, crafts & 0.221 & 0.3 & $1.237 * * *$ & 0.337 \\
\hline Housework, shopping, errands, DIY & -0.002 & 0.187 & 0.197 & 0.286 \\
\hline Listening to music & -0.22 & 0.334 & 0.152 & 0.55 \\
\hline Reading, watching TV, film & $0.350 * *$ & 0.154 & -0.13 & 0.211 \\
\hline Sick in bed & $-1.841^{* * * *}$ & 0.424 & $-1.603 *$ & 0.964 \\
\hline Sleeping, resting, relaxing & -0.085 & 0.254 & -0.36 & 0.315 \\
\hline Something else & 0.162 & 0.162 & $0.489 * *$ & 0.225 \\
\hline Sports, exercise & $0.715^{* *}$ & 0.296 & $1.645^{* * *}$ & 0.372 \\
\hline Talking, chatting, socialising & $0.711 * * *$ & 0.255 & $1.243 * * *$ & 0.289 \\
\hline Travelling, commuting & 0.218 & 0.341 & 0.204 & 0.47 \\
\hline Constant & 0.333 & 0.777 & 0.972 & 0.983 \\
\hline Observations & 1694 & & 1694 & \\
\hline $\mathrm{F}$ & 59.614 & & 35.148 & \\
\hline R squared & 0.623 & & 0.46 & \\
\hline
\end{tabular}

${ }^{* * *}$ Significance at $<1 \%$; $* *$ significance at $<5 \%$; $*$ significance at $<10 \%$. Activity refers to the main activity in the last hour. The following control variables included in the model but not shown here: gender, health, income, marital status, education, parental status, employment status. Reference case for activities is working/studying. Non-significant activities are removed from this table for the purposes of presentation. Heteroskedasticity-robust standard errors

Taken as a whole, these findings evidently lend strong credence to the theoretical validity of our WTP estimates, in line with best practice and established empirical literature (Bateman et al., 2002).

\subsection{Wellbeing analysis}

Table 6 shows the results for Eq. (2) for happiness and purpose in the last hour. We run analysis of momentary wellbeing on a combined sample of survey B (existing users) and survey $\mathrm{C}$ (general population). This allows us to compare the associations between recent use of BoF compared to the range of other activities that individuals report having been doing in the last hour. Having used BoF in the last hour was associated with significantly higher levels of self-reported happiness $(0.18$ points 
on a 11-point scale, $p=0.031)$ and sense of purpose (0.59 points on an 11-point scale, $p=0.000$ ) controlling for known drivers of SWB. The key finding is that these results are significant and positive when controlling for a range of factors known to drive wellbeing.

These results provide evidence that use of BoF is associated with higher levels of self-reported happiness and higher sense of purpose. The results here can be seen as providing supporting evidence to the $\mathrm{CV}$ results at a more micro-level. These results suggest that part of the value that people place in BoF stem from the wellbeing benefits that they feel in terms of happiness and of the sense of purpose from accessing archive film material. To our knowledge, this is the first application of Subjective Wellbeing analysis to digital cultural service offerings.

\section{Discussion}

\subsection{Methodological considerations}

This study contributes to our understanding of the value of cultural heritage in the form of historical film materials, and its preservation and public access through digitalised film archive content. The knowledge gap in this area is particularly glaring given the growth of digital providers of cultural material in the past 5-10 years, and the likely importance of such services in the future in response to the 2020 COVID19 pandemic and the potential that digital services provide for improving access to cultural services for those who are traditionally seen as hard to reach, such as people with disabilities, lower socioeconomic groups, and those who live at geographical distance from physical cultural institutions.

Overall, the study produced user WTP values for BoF of a plausible magnitude and comparable with prices currently charged for other online digital services in the UK. Tests of internal validity showed that WTP was associated with theoretically consistent drivers of value in all scenarios. In particular, household income was a positive and significant determinant of WTP in all models. We must caveat that the use of WTP as the elicitation method in this SP survey, could lead to low valuations compared to the use of WTA values (as demonstrated by the literature on the potentially threefold disparity between WTA and WTP, see e.g. Kim et al., 2015). Thus, while it is important for the purposes of CBA for CV values to be realistic and not subject to the hypothetical biases that can lead to over-estimation of value in SP surveys, we acknowledge that the choice of WTP over WTA can lead to an underestimation of values for public goods. As such, it is important to acknowledge that the plausibly low valuations that we elicit here may also be due to the methodological choice of WTA over WTP, as much as the realism of the survey design.

We have demonstrated that access to cultural archives, in the form of digitalised historical film archive made available through Britain on Film, is positively valued by both users and non-users. CV methods enable us to estimate the value of BoF in terms of the welfare benefits it provides benefits to individuals, interpreted as a direct use value, that people would be willing to pay to continue to access the service. 
These positive welfare benefits are also detected in terms of quality of life measures, with BoF users reporting higher subjective wellbeing (happiness) on average after accessing and consuming the service, compared to those doing other activities in the general population. This provides supporting evidence to the WTP values estimated through traditional preference-based valuation. Indeed, the prices that individuals are willing to pay to consume a good in a competitive market only act as a proxy for the welfare, or utility, they gain from it. These results are in line with previous findings using momentary wellbeing data that show that cultural activities rank very highly in terms of impacts on subjective wellbeing (Fujiwara \& MacKerron, 2015). This provides some rationale for why people are willing to pay to use $\mathrm{BoF}$, while there are other similarly accessible free services on the market (e.g. Youtube, etc.), in terms of the wellbeing benefits that are associated with the direct consumption of BoF.

Many cultural goods will be valued by the public without ever having used them. Non-use value refers to the value that people place on archive film that they may not use themselves, but whose existence they value, and that they want to preserve for others and for future generations. This study therefore looked at the non-use value of BoF and archive work amongst the population who know of BoF and value its existence without having previously used it themselves.

\subsection{Policy implications}

Cultural history, such as that contained within archive film material, contributes to the shared sense of community, identify, and place that make up our intangible culture. Culture receives public spending, meaning that it is subject to Government budget decisions and must make business cases to justify financial support. This involves quantitative methods that allow analysts to make consistent and comparable business case evaluations of the benefits of culture in the face of limited budgets. Government spending decisions in many OECD countries (European Commission, 2008; HM Treasury, 2011; Transport Canada, 1994) require evaluation methods using Cost-Benefit Analysis, whereby outcomes are valued in monetary terms and compared against the costs of investment in order to evaluate their value to society.

The advantage of applying methods from economics to value cultural activities in monetary terms is that it makes cultural goods and services commensurable with other costs and benefits within CBA as applied to cultural policy and investment decisions, putting it on a level footing with other policy areas. However, even within the cultural sector, competition for limited funding resources is strong. Emerging modes of cultural value, such as those that are stored and accessed digitally, currently have a lack of evidence demonstrating their value in welfare terms. This may put digital cultural heritage at a disadvantage compared to more established cultural assets, like cultural institutions, events, and built heritage. Failure to account for the value of digital archive film in monetary terms risks sub-optimal allocation of resources to accessing and preserving these aspects of shared cultural history. To address this gap, our paper provides an empirical study of digital culture using 
established non-market valuation techniques which are applied as standard to more tangible cultural assets.

As outlined in the theoretical framework above, the value of a digital asset like an archive of historic film extends beyond those who currently use it, to those introduced to it who had not previously experienced it, and even to those in the general public who have never directly experienced it. The fact that non-users express positive WTP in the second valuation question (for the archive work behind BoF) indicates that people value the archive work in a way that is additional to the value that is provided through access to it through BoF.

The existence of positive non-use values for both non-use valuation scenarios (WTP to maintain free access to BoF and WTP to support the research and archive work behind BoF) suggests that individuals understand the differences between $\mathrm{BoF}$ and the archive work behind it, and that they value each aspect distinctly. This means that even those members of the general population who have not used BoF previously have a positive value for the societal benefits that BoF provides as a free service to the public, as well as valuing the archive work behind BoF. This gives a strong indication of the value that society places in the existence of $\mathrm{BoF}$ and the archive work behind it.

\section{Conclusion}

Archiving cultural heritage on film allows access to those who may not have had previous access to physical institutions. This is important in providing the right of access to public goods for all. The current survey design allowed the establishment of various use and non-use values for access to a digital archive of historical cultural materials. We found that regardless of whether people use or do not use such services, value is gained from knowing that the cultural heritage continues to be accessible by the public for current and future generations. Wellbeing values were found to be related to recent consumption of the online archive material, which suggests the subjective experience of consuming the digital cultural archive material online positively impacts the consumer's utility. Finally, prior enjoyment of the consumption of the good is related to the consumer's perceived worth of the good in their WTP value. This paper provides a starting point for valuing online cultural values in this emerging service. The area of subjective experience of online cultural goods, and the impact on subjective wellbeing, is to be further explored. 


\section{Appendix 1: Residuals analysis of willingness to pay regressions}

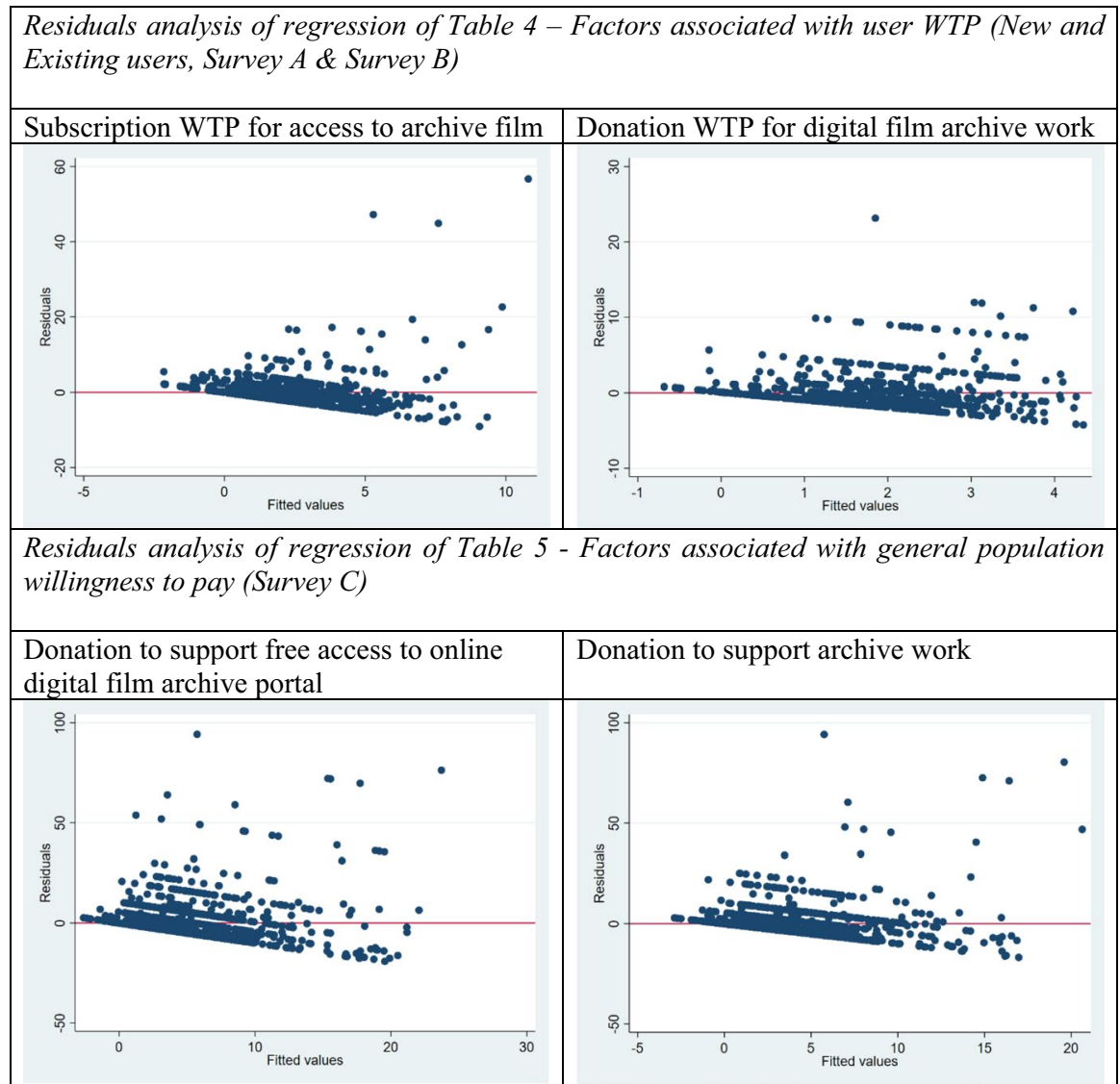

\section{Appendix 2: Alternative model specification: Ordinal regressions}

See Tables 7 and 8 . 
Table 7 Ordinal regression of factors associated with user WTP for Britain on Film (subscription) and the research and archive work behind Britain on Film (top-up donation) (New and Existing users, Survey A and Survey B)

\begin{tabular}{|c|c|c|c|c|}
\hline \multirow[t]{2}{*}{ Variable } & \multicolumn{2}{|c|}{$\begin{array}{l}\text { Subscription WTP for } \\
\text { access to archive film }\end{array}$} & \multicolumn{2}{|c|}{$\begin{array}{l}\text { Donation WTP for } \\
\text { digital film archive } \\
\text { work }\end{array}$} \\
\hline & $b$ & $\mathrm{Se}$ & $b$ & se \\
\hline Gender (female) & -0.027 & 0.149 & -0.143 & 0.149 \\
\hline Age (log) & $0.617 *$ & 0.351 & -0.256 & 0.299 \\
\hline Income $(\log )$ & $0.359 * * *$ & 0.115 & $0.345^{* * *}$ & 0.109 \\
\hline BAME & 0.541 & 0.333 & $0.773 * *$ & 0.314 \\
\hline Education (university) & -0.026 & 0.151 & $0.313^{* *}$ & 0.159 \\
\hline Married/ with partner & -0.023 & 0.169 & -0.242 & 0.167 \\
\hline Employed & 0.252 & 0.239 & 0.181 & 0.246 \\
\hline Student & 0.373 & 0.557 & 0.256 & 0.468 \\
\hline Retired & 0.419 & 0.275 & $0.533 *$ & 0.284 \\
\hline Children & -0.006 & 0.215 & 0.031 & 0.201 \\
\hline Disabled & 0.164 & 0.235 & 0.049 & 0.219 \\
\hline London & -0.082 & 0.277 & 0.316 & 0.267 \\
\hline Rural & 0.056 & 0.158 & -0.198 & 0.162 \\
\hline One-off user & 0.011 & 0.186 & -0.005 & 0.188 \\
\hline First time user & 0.260 & 0.218 & $0.391 *$ & 0.208 \\
\hline Time spent on Britain on Film (hours) in last 2 days & $0.143 * *$ & 0.071 & $0.113^{*}$ & 0.064 \\
\hline Enjoyment of BoF (enjoy/a lot) & $0.656 * * *$ & 0.233 & $0.778 * * *$ & 0.233 \\
\hline Satisfied with content & $0.707 * * *$ & 0.238 & $0.535 * *$ & 0.248 \\
\hline Familiarity with BoF & 0.273 & 0.270 & 0.400 & 0.249 \\
\hline \multicolumn{5}{|l|}{ Familiarity with archive work } \\
\hline Arts, culture, heritage and museums are a fiscal priority & 0.285 & 0.181 & $0.357 * *$ & 0.177 \\
\hline General or specialist knowledge of film & $0.494 * *$ & 0.193 & $0.355^{*}$ & 0.205 \\
\hline Recently used a digital platform & $0.395^{*}$ & 0.226 & 0.153 & 0.226 \\
\hline $\begin{array}{l}\text { Member of heritage, conservation or other similar organi- } \\
\text { sation, including BFI or BFI Player + subscriber }\end{array}$ & 0.127 & 0.170 & 0.093 & 0.166 \\
\hline$B o F$ stopping would reduce my life satisfaction & $0.838 * * *$ & 0.169 & $0.638 * * *$ & 0.166 \\
\hline Observations & 711 & & 703 & \\
\hline R squared & 0.0503 & & 0.0571 & \\
\hline
\end{tabular}

${ }^{* * *}$ Significance at $<1 \%$; **significance at $<5 \%$; *significance at $<10 \%$. Reference group: (i) for gender ref=female; (ii) for education ref=all qualifications under Degree; (iii) for children ref = no children; (iv) for one-off and first-time user ref=repeat user. Heteroskedasticity-robust standard errors. Note, recommend friend excluded from model due to lower sample size. Likely to use BoF again excluded due to collinearity with enjoyment of BoF 
Table 8 Ordinal regression of factors associated with general population willingness to pay an annual donation for Britain on Film and (separate) annual donation to research and archive work (Survey C)

\begin{tabular}{|c|c|c|c|c|}
\hline \multirow[t]{2}{*}{ Variable } & \multicolumn{2}{|c|}{$\begin{array}{l}\text { Donation to support } \\
\text { free access to online } \\
\text { digital film archive } \\
\text { portal }\end{array}$} & \multicolumn{2}{|c|}{$\begin{array}{l}\text { Donation to support } \\
\text { archive work }\end{array}$} \\
\hline & $b$ & $\mathrm{Se}$ & $B$ & se \\
\hline Gender (female) & -0.190 & 0.120 & $-0.253 * *$ & 0.125 \\
\hline Age (log) & $0.721 * * *$ & 0.220 & $0.423^{*}$ & 0.227 \\
\hline Income (log) & $0.216^{* *}$ & 0.090 & $0.340 * * *$ & 0.096 \\
\hline BAME & 0.088 & 0.200 & 0.097 & 0.197 \\
\hline Education (university) & -0.082 & 0.121 & -0.063 & 0.129 \\
\hline Married/ with partner & -0.103 & 0.136 & $-0.335^{* *}$ & 0.141 \\
\hline Employed & 0.349 & 0.213 & 0.323 & 0.216 \\
\hline Student & $0.885^{* * *}$ & 0.297 & $0.731 * *$ & 0.307 \\
\hline Retired & 0.396 & 0.253 & 0.414 & 0.256 \\
\hline Children & -0.107 & 0.141 & -0.122 & 0.155 \\
\hline Disabled & 0.256 & 0.182 & 0.297 & 0.185 \\
\hline London & 0.192 & 0.218 & 0.204 & 0.213 \\
\hline Rural & 0.117 & 0.124 & -0.020 & 0.132 \\
\hline Familiarity with BoF & $0.926 * * *$ & 0.256 & & \\
\hline Familiarity with archive work & NA & NA & $0.942 * * *$ & 0.270 \\
\hline Arts, culture, heritage and museums are a fiscal priority & $0.364 * *$ & 0.167 & $0.515^{* * *}$ & 0.185 \\
\hline General or specialist knowledge of film & $0.702 * * *$ & 0.146 & $0.773 * * *$ & 0.159 \\
\hline Recently used a digital platform & $0.628 * * *$ & 0.164 & $0.496 * * *$ & 0.172 \\
\hline $\begin{array}{l}\text { Member of heritage, conservation or other similar organi- } \\
\text { sation, including BFI or BFI Player + subscriber }\end{array}$ & $0.652 * * *$ & 0.130 & $0.622 * * *$ & 0.140 \\
\hline Britain on Film stopping would reduce my life satisfaction & $0.899 * * *$ & 0.139 & $0.969 * * *$ & 0.143 \\
\hline Constant & $-19.742 * * *$ & 7.300 & $-13.677^{*}$ & 7.063 \\
\hline Observations & 1,230 & & 1,225 & \\
\hline $\mathrm{R}$ squared & 0.0504 & & 0.0586 & \\
\hline
\end{tabular}

\footnotetext{
${ }^{* * *}$ Significance at $<1 \%$; **significance at $<5 \%$; *significance at $<10 \%$. Reference group: (i) for gender ref=female; (ii) for education $r e f=$ all qualifications under Degree; (iii) for children ref = no children; (iv) for new user ref=existing user. Heteroskedasticity-robust standard errors
}

Acknowledgements Our thanks to Madeleine Arber for her helpful comments on the final draft of this paper.

Funding We are grateful to the British Film Institute for funding this research.

\section{Declarations}

Conflict of interest Daniel Fujiwara has received research grants from the British Film Institute. 


\section{References}

Allcott, H., Braghieri, L., Eichmeyer, S., \& Gentzkow, M. (2020). The welfare effects of social media. American Economic Review, 110(3), 629-676. https://doi.org/10.1257/aer.20190658

Andersson, T. D., Armbrecht, J., \& Lundberg, E. (2012). Estimating use and non-use values of a music festival. Scandinavian Journal of Hospitality and Tourism, 12(3), 215-231. https://doi.org/10.1080/ 15022250.2012.725276

Arrow, K., \& Solow, R. (1993). Report of the NOAA panel on contingent valuation. National Oceanic and Atmospheric Administration Washington, DC. Retrieved 28 May, 2014 http://www.cbe.csueastbay. edu/ alima/courses/4306/articles/NOAA\%20on\%20contingent\%20valuation\%201993.pdf

Bakhshi, H., Fujiwara, D., Lawton, R. N., Mourato, S., \& Dolan, P. (2015). Measuring economic value in cultural institutions (Cultural Value Project) (p. 103). Arts and Humanities Research Council. https://ahrc.ukri.org/documents/project-reports-and-reviews/measuringeconomicvalue/

Bateman, I., Carson, R. T., Day, B., Hanemann, M., Hanley, N., Hett, T., et al. (2002). Economic valuation with stated preference techniques: A manual. Edward Elgar.

Bedate, A. M., Herrero, L. C., \& Sanz, J. Á. (2009). Economic valuation of a contemporary art museum: Correction of hypothetical bias using a certainty question. Journal of Cultural Economics, 33(3), 185-199. https://doi.org/10.1007/s10824-009-9098-y

Brynjolfsson, E., Collis, A., Diewert, W. E., Eggers, F., \& Fox, K. J. (2019). GDP-B: Accounting for the value of new and free goods in the digital economy (working paper no. 25695). National Bureau of Economic Research. https://doi.org/10.3386/w25695

Cameron, T. A., \& Huppert, D. D. (1989). OLS versus ML estimation of non-market resource values with payment card interval data. Journal of Environmental Economics and Management, 17(3), 230-246. https://doi.org/10.1016/0095-0696(89)90018-1

Cazzetta, S. (2008). From the Salon Indien Du Grand Café to Youtube. . Erasmus University.

Champ, P. A., \& Bishop, R. C. (2001). Donation payment mechanisms and contingent valuation: An empirical study of hypothetical bias. Environmental and Resource Economics, 19(4), 383-402.

Clark, A. E., \& Oswald, A. J. (2002). A simple statistical method for measuring how life events affect happiness. International Journal of Epidemiology, 31(6), 1139-1144. https://doi.org/10.1093/ije/31.6.1139

Crossick, G., \& Kaszynska, P. (2016). Understanding the value of arts \& culture. The AHRC Cultural Value Project. . AHRC.

Csikszentmihalyi, M., \& Hunter, J. (2003). Happiness in everyday life: The uses of experience sampling. Journal of Happiness Studies, 4(2), 185-199. https://doi.org/10.1023/A:1024409732742

Cummings, R. G., \& Taylor, L. O. (1999). Unbiased value estimates for environmental goods: A cheap talk design for the contingent valuation method. The American Economic Review, 89(3), 649-665.

Dolan, P., Fujiwara, D., \& Metcalfe, R. (2011). A step towards valuing utility the marginal and cardinal way (CEP discussion paper no. 1062). Centre for Economic Performance, LSE. Retrieved 21 May, 2014 http://ideas.repec.org/p/cep/cepdps/dp1062.html

Eftec. (2005). Valuation of the historic environment the scope for using results of valuation studies in the appraisal and assessment of heritage-related projects and programmes (p. 90). Economics for the Environment Consultancy. http://www.english-heritage.org.uk/publications/valuation-historic-envir onment/valuation-historic-environment-final-rep.pdf

Ferrer-i-Carbonell, A., \& Frijters, P. (2004). How important is methodology for the estimates of the determinants of happiness? The Economic Journal, 114(497), 641-659. https://doi.org/10.1111/j.14680297.2004.00235.x

Fujiwara, D., \& Campbell, R. (2011). Valuation techniques for social cost-benefit analysis: Stated preference, revealed preference and subjective well-being approaches. A discussion of the current issues (pp. 1-76). HM Treasury. Retrieved 13 April, 2013 https://www.gov.uk/government/uploads/system/uploads/attachment_data/file/209107/greenbook_valuationtechniques.pdf

Fujiwara, D., Lawton, R. N., \& Mourato, S. (2017). The health and wellbeing benefits of public libraries. Economia della Cultura. https://doi.org/10.1446/87272

Fujiwara, D., \& MacKerron, G. (2015). Cultural activities, artforms and wellbeing (p. 37). SImetrica, Arts Council England. http://media.wix.com/ugd/9ccf1d_05c61fa6c3ee4ea68de17ce62f71cd53.pdf

European Commission. (2008). Guide to cost-benefit analysis of major projects (p. 257). Evaluation Unit, DG Regional Policy, European Commission. http://ec.europa.eu/regional_policy/sources/docgener/ guides/cost/guide2008_en.pdf 
Haab, T. C., Interis, M. G., Petrolia, D. R., \& Whitehead, J. C. (2013). From hopeless to curious? Thoughts on Hausman's "Dubious to Hopeless" critique of contingent valuation. Applied Economic Perspectives and Policy. https://doi.org/10.1093/aepp/ppt029

Haab, T. C., \& McConnell, K. E. (2002). Valuing environmental and natural resources: The econometrics of non-market valuation. . Edward Elgar Publishing.

Hanemann, M., Loomis, J., \& Kanninen, B. (1991). Statistical efficiency of double-bounded dichotomous choice contingentvaluation. American Journal of Agricultural Economics, 73(4), 1255-1263. https://doi.org/10.2307/1242453.

Hanley, N., Mourato, S., \& Wright, R. E. (2001). Choice modelling approaches: A superior alternative for environmental valuation? Journal of Economic Surveys, 15(3), 435-462. https://doi.org/10.1111/ $1467-6419.00145$

Hausman, J. (2012). Contingent valuation: From dubious to hopeless. Journal of Economic Perspectives, 26(4), 43-56. https://doi.org/10.1257/jep.26.4.43

HM Treasury (2011). The green book: Appraisal and evaluation in central government (pp. 1-114). HM Treasury. Retrieved 21 May, 2014. https://www.gov.uk/government/uploads/system/uploads/attac hment_data/file/220541/green_book_complete.pdf

Hobbs, J. (2016). Engagement and willingness to pay for short form animation content online. The International Journal of Design Management and Professional Practice, 10(2), 19-40.

Horowitz, J. K., \& McConnell, K. E. (2002). A Review of WTA/WTP studies. Journal of Environmental Economics and Management, 44(3), 426-447. https://doi.org/10.1006/jeem.2001.1215

Juutinen, A., Mitani, Y., Mäntymaa, E., Shoji, Y., Siikamäki, P., \& Svento, R. (2011). Combining ecological and recreational aspects in national park management: A choice experiment application. Ecological Economics, 70(6), 1231-1239.

Kahneman, D., Krueger, A. B., Schkade, D. A., Schwarz, N., \& Stone, A. A. (2004). A survey method for characterizing daily life experience: The day reconstruction method. Science, 306(5702), 17761780. https://doi.org/10.1126/science. 1103572

Kaldor, N. (1939). Welfare propositions of economics and interpersonal comparisons of utility. The Economic Journal, 49(195), 549-552. https://doi.org/10.2307/2224835

Kim, Y., Kling, C. L., \& Zhao, J. (2015). Understanding behavioral explanations of the WTP-WTA divergence through a neoclassical lens: Implications for environmental policy. Annual Review of Resource Economics, 7(1), 169-187. https://doi.org/10.1146/annurev-resource-100913-012501

Koń, B., \& Jakubczyk, M. (2019). Is the literature on the WTP-WTA disparity biased? Journal of Behavioral and Experimental Economics, 82, 101460. https://doi.org/10.1016/j.socec.2019.101460

Lawton, R. N., Mourato, S., Fujiwara, D., \& Bakhshi, H. (2019). Comparing the effect of oath commitments and cheap talk entreaties in contingent valuation surveys: A randomised field experiment. Journal of Environmental Economics and Policy,. https://doi.org/10.1080/21606544.2019.1689174

MacKerron, G., \& Mourato, S. (2013). Happiness is greater in natural environments. Global Environmental Change, 23(5), 992-1000. https://doi.org/10.1016/j.gloenvcha.2013.03.010

Maddison, D., \& Foster, T. (2003). Valuing congestion costs in the British Museum. Oxford Economic Papers, 55(1), 173-190. https://doi.org/10.1093/oep/55.1.173

Maddison, D., \& Mourato, S. (2001). Valuing different road options for Stonehenge. Conservation and Management of Archaeological Sites, 4(4), 203-212. https://doi.org/10.1179/135050301793138182

Mourato, S., \& Mazzanti, M. (2002). Economic valuation of cultural heritage: Evidence and prospects. In M. de la Torre (Ed.), Assessing the Values of Cultural Heritage (pp. 51-76). Getty Conservation Institute. http://hdl.handle.net/10020/gci_pubs/values_cultural_heritage

Noonan, D. S. (2003). Contingent valuation and cultural resources: A meta-analytic review of the literature. Journal of Cultural Economics, 27(3-4), 159-176. https://doi.org/10.1023/A:1026371110799

OECD. (2017). How's life? 2017. Measuring well-being (p. 462). OECD Publishing. http://www.oecd. org/statistics/how-s-life-23089679.htm

Oguz, S., Merad, S., \& Snape, D. (2013). Measuring national well-being: What matters most to personal wellbeing? (p. 59). Office for National Statistics. Retrieved 5 May, 2014. http://www.ons.gov.uk/ ons/dcp171766_312125.pdf

Ongena, G. (2013). A consumer perspective on moving images: The design and adoption of public audiovisual heritage services in the Netherlands. . Twente: Universiteit Twente.

Pearce, D., Atkinson, G., \& Mourato, S. (2006). Cost-benefit analysis and the environment. In Recent developments, organisation for economic co-operation and development 
Pearce, D., \& O’zdemiroglu, E. (2002). Economic valuation with stated preference techniques. Department for Transport, Local Government and the Regions. https:/www.gov.uk/government/uploads/system/ uploads/attachment_data/file/191522/Economic_valuation_with_stated_preference_techniques.pdf

Pung, C., Clarke, A., \& Patten, L. (2004). Measuring the economic impact of the British library. New Review of Academic Librarianship, 10(1), 79-102. https://doi.org/10.1080/13614530412331296826

Sen, A. K. (1985). Commodities and capabilities. . North-Holland.

Sen, A. K. (1999). Development as freedom. . Oxford University Press.

Sriarkarin, S., \& Lee, C.-H. (2018). Integrating multiple attributes for sustainable development in a national park. Tourism Management Perspectives, 28, 113-125. https://doi.org/10.1016/j.tmp.2018. 08.007

Steele, D. (2004). Developing the evidence base for UK film strategy: The research process at the UK Film Council. Cultural Trends, 13(4), 5-21. https://doi.org/10.1080/0954896042000318029

Sunstein, C. R. (2019). Valuing Facebook. Behavioural Public Policy, . https://doi.org/10.1017/bpp.2018. 34

Throsby, C. D., \& Withers, G. A. (1986). Strategic bias and demand for public goods. Journal of Public Economics, 31(3), 307-327. https://doi.org/10.1016/0047-2727(86)90063-0

Throsby, D. (2001). Economics and culture. . Cambridge University Press.

Throsby, D. (2003). Determining the value of cultural goods: How much (or how little) does contingent valuation tell us? Journal of Cultural Economics, 27(3-4), 275-285. https://doi.org/10.1023/A: 1026353905772

Transport Canada. (1994). Guide to benefit-cost analysis in transport Canada (p. 105). Economic Evaluation Branch, Transport Canada. http://www.evaluaciondeproyectos.es/EsWeb/Recursos/guias_acb/ PDF/3.pdf

Tunçel, T., \& Hammitt, J. K. (2014). A new meta-analysis on the WTP/WTA disparity. Journal of Environmental Economics and Management, 68(1), 175-187. https://doi.org/10.1016/j.jeem.2014.06. 001

Vaughan, W. J., Russell, C. S., Rodriguez, D. J., \& Darling, A. C. (2000). Uncertainty in cost-benefit analysis based on referendum contingent valuation. mpact Assessment and Project. Appraisal, 18(2), 125-137. https://doi.org/10.3152/147154600781767466.

Wheatley, D., \& Bickerton, C. (2017). Subjective well-being and engagement in arts, culture and sport. Journal of Cultural Economics, 41(1), 23-45.

Willis, K. G. (2014). The use of stated preference methods to value cultural heritage. In Handbook of the economics of art and culture, volume 2 (pp. 145-181). Elsevier. https://doi.org/10.1016/B978-0444-53776-8.00007-6

Zong, C., Cheng, K., Lee, C.-H., \& Hsu, N.-L. (2017). Capturing tourists' preferences for the management of community-based ecotourism in a forest park. Sustainability, 9(9), 1673. https://doi.org/10. 3390/su9091673

Publisher's Note Springer Nature remains neutral with regard to jurisdictional claims in published maps and institutional affiliations.

\section{Authors and Affiliations}

\section{Ricky N. Lawton ${ }^{1}$ D $\cdot$ Daniel Fujiwara ${ }^{2}$ - Ulrike Hotopp $p^{1,3}$}

Ricky N. Lawton

ricky_lawton@hotmail.com

Daniel Fujiwara

d.fujiwara@simetrica.co.uk

Ulrike Hotopp

uhotopp@gmail.com

1 Simetrica-Jacobs, The Shepherds Building West Entrance, Rockley Road, Shepherds Bush, 
London W14 0DA, UK

2 Simetrica-Jacobs, The Shepherds Building West Entrance, Rockley Road, Shepherds Bush, London W14 0DA, UK

3 University of Kent, Canterbury, UK 